American Journal of Applied Sciences 8 (1): 15-25, 2011

ISSN 1546-9239

(C) 2010 Science Publications

\title{
Germination Time Dependence of Bioactive Compounds and Antioxidant Activity in Germinated Rough Rice (Oryza sativa L.)
}

\author{
Anuchita Moongngarm and Ekkalak Khomphiphatkul \\ Department of Food Technology and Nutrition, Faculty of Technology \\ Mahasarakham University, Mahasarakham, 44150, Thailand
}

\begin{abstract}
Problem statement: Germinated rice has been recognized as a functional food and its health benefits. However, most related studies were on germinated brown rice but our previous study indicated that germination of rough rice was an effective method to obtain high concentrations of bioactive compounds. Germination time is one of the most important factors affecting the level of biochemical compositions and antioxidant activity. Approach: Rough rice seeds were soaked in water for 2 days and germinated for four different days (1- 4 days). Total phenolic compounds, phytic acid, $\alpha$-tocopherol, $\gamma$ tocopherol, $\alpha$-tocotrienol and $\gamma$-oryzanol were investigated compared with those of ungerminated brown rice. The antioxidant activity of germinated rice was evaluated through four different methods, the 1, 1Diphenyl-2-Picrylhydrazyl (DPPH) free radical scavenging assay, hydroxyl radical scavenging activity, lipid peroxidation assay and linoleic acid emulsion system-thiocyanate method. Results: The results showed that the germination for 2 days or longer, after soaking, yielded significantly higher level of total phenolic, $\alpha$-tocopherol, $\gamma$-tocopherol, $\alpha$-tocotrienol and $\gamma$-oryzanol than those of ungerminated brown rice and soaked rice, whilst the concentration of phytic acid was reduced significantly when germination time was increased. The samples germinated for one day or longer also revealed greater antioxidant activity than those of ungerminated rice. Conclusion: The level of bioactive compounds and antioxidant activity of germinated rough rice were affected by germination time. Germination for 2 and 3 days was the optimum time for germination rough rice to obtain high concentration of bioactive compounds and high antioxidant activity. The germination process of rough rice could be a potential method to obtain functional germinated rice flour with high bioactive compounds and health beneficial properties and could be applied to produce functional food products.
\end{abstract}

Key words: Germinated brown rice, germinated rough rice, bioactive compounds, Brown Rice (BR), Dried Matter (DM), Total Phenolic Compounds (TPC), Gallic Acid Equivalents (GAE), Malonaldehyde (MDA), original weight

\section{INTRODUCTION}

Germinated rice has gained a lot of attention nowadays as it contains higher amount of bioactive compounds than those of ungerminated brown rice. It is an excellent source of $\gamma$-oryzanol, tocopherols and tocotrienols, which offer beneficial health properties and antioxidant activity (Ryynanen et al., 2004). A number of studies have reported on the health benefits of tocopherols, tocotrienols and $\gamma$-oryzanol, such as lowering the risk of cancer formation, coronary heart diseases and cholesterol (Imsanguan et al., 2008; Rohrer and Siebenmorgen, 2004), having antiinflammatory activity and inhibiting cholesterol oxidation (Akihisa et al., 2000; Rong et al., 1997;
$\mathrm{Xu}$ et al., 2001). Furthermore, more attention has been paid to the antioxidant contained in foods which epidemiological studies have shown that high antioxidant intake can be associated with decreasing the risk of cardiovascular disease and some types of cancer (Johanna, 1999). Antioxidants can delay the oxidation of an oxidizable substrate in a chain reaction, thus the antioxidants in rice have a potential use as a food additive, which can improve the storage stability of a variety of food (Aguilar-Garcia et al., 2007; Febles et al., 2002; Nanua et al., 2000; Sereewatthanawut et al., 2008; Watchararuji et al., 2008).

Various studies on germination of rice reported different conditions on germination process depending on purposes of studies and most of them studied the

Corresponding Author:Anuchita Moongngarm, Department of Food Technology and Nutrition, Faculty of Technology, Mahasarakham University, Mahasarakham 44150, Thailand Tel: +66-43-754086 Fax: +66-43-754086 
effect of germination on the content of bioactive compounds in brown rice (Banchuen et al., 2009; SieCheong et al., 2009; Ohtsubo et al., 2005). Only few studies have been done on changes of bioactive compounds and antioxidant activity in rough rice as affected by germination time. Our previous study on the comparison of chemical compositions and bioactive compounds of germinated rough rice and germinated brown rice (Moongngarm and Saetung, 2010) revealed that germinated rough rice contained higher level of nutrients and bioactive compounds than those of germinated brown rice and ungerminated brown rice. In the fore mentioned study, the germinated rice was achieved by following the method reported by Saetung (2008), which only little information regarding changes of bioactive compounds from different times of germination was shown and generally only proximate compositions were illustrated. Several factors affect changes of biochemical compositions and bioactive compounds of germinated rice such as moisture content of the rice seed, rice type and germination temperature. Germination time is one of the most important factors affecting on the accumulation of compounds. Fernandez-Orozco et al. (2008) reported that bioactive compounds accumulation in germinated soybean and mung bean was germination time dependence. Similar to that study on germination of broccoli and radish seeds by Martinez-Villaluenga et al. (2010) who found that germination time influenced the level of bioactive compounds and antioxidant activity. Therefore the present study was conducted to investigate the influence of germination times on the content of major bioactive compounds and antioxidant activity and to obtain germinated rice product with a high content in bioactive compounds and antioxidant activity. In this study, rough rice of Oryza sativa L., cultivar RD-8, was selected. It is one of the most popular waxy rice cultivars for consuming in the Northeast of Thailand.

\section{MATERIALS AND METHODS}

Materials: Rice samples: Rough rice of Oryza sativa L., cultivar RD-8 was purchased from a local ricemilling factory in Mahasarakham province, Thailand. Ungerminated Brown Rice (BR) was prepared by removing a husk of the ungerminated rough rice using a laboratory de-husker.

Germinated rough rice preparation: Rough rice seeds were soaked in tap water $(\mathrm{pH}$ 6.6) at room temperature for 2 days (S48) (40\% moisture content) and water was changed every 7-8 h. The steeped kernels were placed in plastic baskets and covered by cheese cloth. Germination took place in a germinating cabinet for 1 day (GR1), 2 days (GR2), 3 days (GR3) and 4 days (GR4) at $28-30^{\circ} \mathrm{C}$ and $90-95 \%$ relative humidity using an automatic sprinkler. The germinated seeds from each germination time were dried at $50^{\circ} \mathrm{C}$ to approximately $10 \%$ of moisture content. The hull, root and shoot were separated using laboratory de-husker. All samples were performed in triplicates. Germinated rice samples were stored at $-20^{\circ} \mathrm{C}$ and finely ground (40 mesh) prior to analyses.

The rice grains were considered as a germinated seeds when the young radicle, white root emerging from the lower end of the rice seed, was visible. The germination rate was investigated by sampling approximate 200-300 grains from the germinated basket and the germinated seeds were counted. The results of three replicates were calculated, as the percentage of germinated kernels to total kernels used.

Methods: Determination of moisture content, protein content, reducing sugar and $\alpha$-amylase activity: Moisture content was determined using oven-drying at $105^{\circ} \mathrm{C}$ to a constant weight. Crude protein content was measured using standard methods of AOAC (1990), calculated from nitrogen content using Kjeldahl method (Gerhardt, Germany) and multiplied by a factor of 5.95 . Reducing sugar was determined by following the method of Somogyi (1952). All determinations were expressed as percent of Dried Matter (DM) basis. The $\alpha$-amylase activity was assayed using the enzyme assay kits (Megazyme International, Ireland).

Determination of total phenolic compounds and phytic acid: The content of Total Phenolic Compounds (TPC) of the rice products was determined by FolinCiocaltue reagent (Iqbal et al., 2005). The reaction was initiated by mixing $0.2 \mathrm{~mL}$ of appropriate diluted rice bran extracts, $0.8 \mathrm{~mL}$ of freshly prepared diluted FolinCiocaltue reagent and $2 \mathrm{~mL}$ of $7.5 \%$ sodium carbonate. The final mixture was diluted to $7 \mathrm{~mL}$ with deionized water. The mixture was kept in the dark at an ambient temperature for $2 \mathrm{~h}$. The absorbance at $765 \mathrm{~nm}$ was measured, using a UV-Vis spectrophotometer (Shimadzu, Japan). The results of the total phenolic compounds were expressed as $\mathrm{mg}$ Gallic Acid Equivalents (GAE) per $g$ of rice flour. Phytic acid was determined following Garcia-Estepa et al. (1999).

Determination of $\alpha$-tocopherols, $\gamma$-tocopherol, $\alpha$ tocotrienol and $\gamma$-oryzanol: The determination of these compounds was carried out according to the method reported by Ryynanen et al., (2004) and Chen and Bergman (2005) with some modifications. The rice flour (0.5g dry weight) was accurately weighed into a 
glass tube. Ascorbic acid $(0.1 \mathrm{~g})$, ethanol $(5 \mathrm{~mL})$ and deionized water $(2 \mathrm{~mL})$ were added and mixed well with a vortex mixer before $\mathrm{KOH}(0.5 \mathrm{~mL})$ was added. The tube was capped and transferred to a boiling water bath for $25 \mathrm{~min}$ and mixed by the vortex mixer every 5 min, while boiling. The tube was cooled in an ice-water bath and then $2.5 \mathrm{~mL}$ of deionized water and $2.5 \mathrm{~mL}$ of ethanol were added to the cooled tube. An unsaponified layer was extracted three times, using $10 \mathrm{~mL}$ of the mixture of $n$-hexane and ethyl acetate $(8: 2)$. The tube was shaken for $10 \mathrm{~min}$ and the organic layers were collected, using a separation funnel. These organic extracts were washed three times with water and evaporated by a rotary evaporator (Buchi, Switzerland). The residue was dissolved in methanol. Prior to HPLC analysis, the extracts were filtered through a $0.45 \mathrm{~mm}$ syringe filter. An analysis of $\gamma$-oryzanol and $\alpha$ tocopherol, $\gamma$-tocopherol and $\alpha$-tocotrienol was performed, using the Reversed Phase High Performance Liquid Chromatography (RP-HPLC). The Shimadzu HPLC system (model L-6200A), equipped with a Photo diode array detector (Shimadzu, Japan) and a computer system, was applied. The spectra, from 250-600 nm, were recorded for all peaks. The extracted samples were injected through a guard-column and separated on a $\mathrm{C}_{18}$ column $(4.60 \times 150 \mathrm{~mm}, 4 \mu \mathrm{m})$ (Phenomenex, USA). Gradient elution was then applied. Mobile phases $\mathrm{A}, \mathrm{B}$ and $\mathrm{C}$ were methanol, water and buthanol, respectively. The gradient was as follows: $0-12 \mathrm{~min}$ $92 \% \mathrm{~A}, 4 \% \mathrm{~B}$ and $4 \% \mathrm{C}: 12-25$ min linear gradient, from $4-3 \% \mathrm{~B}$ and $4-5 \% \mathrm{C}$, with flow rate of $1.5 \mathrm{~mL}$ $/ \mathrm{min}$ and injection volume of $20 \mu \mathrm{L}$. The $\alpha$-tocopherol, $\gamma$-tocopherol and $\alpha$-tocotrienol were detected at $292 \mathrm{~nm}$ and $\gamma$-oryzanol was detected at $325 \mathrm{~nm}$. Chromatograms were recorded and peak areas were used to calculate the content of $\gamma$-oryzanol and $\alpha$ tocopherol, $\gamma$-tocopherol and $\alpha$-tocotrienol against the standard curve of standards.

Determination of antioxidant activity: Antioxidant activity of germinated rice samples and standards (Buylated Hydroxyanisole (BHA) and $\alpha$-tocopherol) was determined using four different methods. All samples were analyzed in triplicate. Antioxidant activity was calculated in two different ways, the first, percent inhibition relative to control was plotted against the sample extract concentrations in order to investigate a dose dependent percent inhibition. The second way was finding the concentration of the sample required to scavenge $50 \%$ of radicals $\left(\mathrm{IC}_{50}\right)$ of each sample using logarithmic regression equation. In order to obtain a logarithmic regression equation, a logarithmic regression curve was established by using the percent inhibition of five different extract concentrations plotted against the sample extract concentrations. Then, the $\mathrm{IC}_{50}$ value was calculated back to the original weight $(\mathrm{mg})$ of rice flour and expressed as the dry matter of rice flour per one $\mathrm{mL}$ of solvent extract. The methods applied to evaluate the antioxidant activity are followings.

DPPH radical scavenging assay: Free radical scavenging activities of rice flour extracts was determined using a stable DPPH free radical following a previously reported method reported by Dasgupta and De (2004) with some modifications. Briefly, the extracts $(1 \mathrm{~mL})$ were added to $5 \mathrm{~mL}$ of a freshly prepared solution of $0.004 \%$ methanolic solution of DPPH. The control sample (negative control) contained $1 \mathrm{~mL}$ methanol without extract plus methanol $(5 \mathrm{~mL})$. BHA and $\alpha$-tocopherol were used as the standard antioxidants for comparison. The absorbance at $517 \mathrm{~nm}$ was measured, using a UV-visible spectrophotometer (Shimadzu, Japan) after incubation for 30 minutes in the dark, at room temperature. The percent inhibition activity was calculated as $\left[\left(\mathrm{A}_{\text {control }}-\mathrm{A}_{\text {sample }}\right) / \mathrm{A}_{\text {control }}\right] \times 100$ $\left(\mathrm{A}_{\text {control }}=\right.$ Absorbance without extracts; $\mathrm{A}_{\text {sample }}=$ Absorbance with extracts). The radical scavenging activity of rice bran extract was expressed as $50 \%$ inhibition concentration, IC50 ( $\left.\mathrm{mg} \mathrm{mL}^{-1}\right)$.

Hydroxyl radical scavenging activity: The effect of hydroxyl radical was assayed by using the 2deoxyribose oxidation method (Sakanaka et al., 2005). 2- Deoxyribose is oxidized by hydroxyl radical that is formed by Fenton reaction and degraded to malondialdehyde. The reaction mixture contained 0.45 $\mathrm{mL}$ of $0.2 \mathrm{M}$ sodium phosphate buffer ( $\mathrm{pH} 7.4), 0.15$ $\mathrm{mL}$ of $10 \mathrm{mM}$ 2- deoxyribose, $0.15 \mathrm{mM}$ of $\mathrm{FeSO}_{4}$ EDTA, $0.15 \mathrm{ml}$ of $10 \mathrm{mM}$ hydrogen peroxide, $0.525 \mathrm{ml}$ of distilled water and $0.1 \mathrm{~mL}$ of extract solution. The reaction was started by the addition of hydrogen peroxide. After incubation at $37^{\circ} \mathrm{C}$ for $4 \mathrm{~h}$, the reaction was stopped by adding $0.75 \mathrm{~mL}$ of $2.8 \%$ Trichloroacetic Acid (TCA) and $0.75 \mathrm{~mL}$ of $1.0 \%$ of thiobarbitiric acid. The mixture was boiled for $10 \mathrm{~min}$, cooled in ice bath and then measured at $520 \mathrm{~nm}$. Percent inhibition of deoxyribose degradation by hydroxyl radical was calculated as $\left[\left(\mathrm{A}_{\text {control }^{-}}\right.\right.$ $\left.\left.\mathrm{A}_{\text {sample }}\right) / \mathrm{A}_{\text {control }}\right] \times 100$, where $\mathrm{A}$ was the absorbance of using sample or control. $\alpha$-Tocopherol and BHT were used as the positive controls. The hydroxyl radical scavenging activity of the sample was expressed as the $\mathrm{IC}_{50} \mathrm{~g} \mathrm{~mL}^{-1}$.

Lipid peroxidation assay: Lipid peroxidation was used to measure the lipid peroxide formed in egg yolk 
homogenate as lipid-rich media (Dasgupta and De, 2004). Egg yolk homogenate $(0.5 \mathrm{~mL}$ of $10 \% \mathrm{v} / \mathrm{v})$ and $0.1 \mathrm{~mL}$ of extract were added to a test tube and made up to 1.0 $\mathrm{mL}$ with distilled water. Subsequently $0.05 \mathrm{~mL}$ of $0.07 \mathrm{M}$ $\mathrm{FeSO}_{4}$ was added to induce lipid peroxidation and the mixture was incubated at room temperature for $30 \mathrm{~min}$. The $1.5 \mathrm{~mL}$ of $20 \%$ acetic acid $(\mathrm{pH} 3.5)$ and $1.5 \mathrm{~mL}$ of $0.8 \%(\mathrm{w} / \mathrm{w})$ thiobarbituric acid in $1.1 \%$ sodium dodecyl sulphate were combined. The resulting mixture was vortexed and heated at $95^{\circ} \mathrm{C}$ for $60 \mathrm{~min}$. After cooling, $5.0 \mathrm{~mL}$ of butanol were added to each tube and centrifuged at $3000 \mathrm{rpm}$ for $10 \mathrm{~min}$. The absorbance of supernatant was measured at $532 \mathrm{~nm}$. Percent inhibition of lipid peroxidation was calculated as $\left[\left(\mathrm{A}_{\text {control }}-\mathrm{A}_{\text {sample }}\right) /\right.$ $\left.\mathrm{A}_{\text {control }}\right] \times 100$. Inhibition of lipid peroxidation was expressed as $\mathrm{IC}_{50}$ values.

Linoleic acid emulsion system-thiocyanate method: The Linoleic acid emulsion system-thiocyanate method (Suja et al., 2005) was used to evaluate the antioxidant activity of the germinated rice. The reaction mixture was made up of $0.28 \mathrm{~g}$ linoleic acid, $0.28 \mathrm{~g}$ of tween 20 and $50 \mathrm{~mL}$ of phosphate buffer (0.2M, pH 7.0), $2.5 \mathrm{~mL}$ of the linoleic acid emulsion, $0.5 \mathrm{~mL}$ of test sample and $2.5 \mathrm{~mL}$ of phosphate buffer $(0.2 \mathrm{M}, \mathrm{pH} 7.0)$. The mixture was mixed and incubated at $37^{\circ} \mathrm{C}$ for $120 \mathrm{~h}$. The mixture prepared by using $0.5 \mathrm{~mL}$ of methanol to replace the test sample was served as the control sample. Readings were taken every $24 \mathrm{~h}$, by taking 0.1 $\mathrm{mL}$ of the mixture and then mixing it with $5.0 \mathrm{~mL}$ of $75 \%$ ethanol, $0.1 \mathrm{~mL}$ of $30 \%$ ammonium thiocyanate and $0.1 \mathrm{~mL}$ of $20 \mathrm{mM}$ ferrous chloride in $35 \% \mathrm{HCL}$. This mixture was reacted at room temperature for $3 \mathrm{~min}$ and the absorbance was measured at $500 \mathrm{~nm}$.

Statistical analysis: All experiments were conducted in triplicate and the results are expressed as mean $\pm \mathrm{SD}$. The statistical examination of the data was performed by the SPSS version 11.5 program using one-way Analysis Of the Variance (ANOVA). The means were compared using the Duncan Multiple Range Test and $\mathrm{p}<0.05$ was applied to establish significant differences.

\section{RESULTS}

The effect of germination on some physical properties of germinated rice is shown in Table 1. Moisture content of rice seed before soaking was $11 \%$ and dramatically increased to $40 \%$ when soaked in water for 2 days. The moisture content of the rice seeds was further increased slightly to $44 \%$ after germinated for 1 day and stable until the end of germination process (4 days). The germination of seeds was observed at the first day with the germination rate of $43.33 \%$ and reached the maximum (88.33-99.33\%) after germination for longer than 2 days. The yield of germinated rice was between 85.57 and $89.20 \%$ and significantly reduced when germinated for 4 days $(84.33 \%)$. The length of shoot and root of germinated seeds were increased $(\mathrm{p}<0.05)$ with germination times.

The influence of germination on $\alpha$ - amylase activity, reducing sugar and protein content are indicated in Table 2. Germination time significantly improved $\alpha$ - amylase activity, reducing sugar and protein content. The $\alpha$-amylase showed the highest activity (38.26 $\mathrm{U} \mathrm{g}^{-1}$ rice flour) when germination for 3 days, approximately 30 times higher than that of S48 and slightly decreased after the 4th day (31.42 $\mathrm{U} \mathrm{g}^{-1}$ ). The content of reducing sugar was found to be highest $(\mathrm{p}<0.05)$ when germinated for 3 and 4 days with the level of 2.41 and $2.70 \%$ respectively, approximately 12.68 and 14.21 times higher than that of BR. The protein content of BR and S48 was 8.69 and $8.15 \%$, respectively and was increased to $10.33-11.08 \%$ $(\mathrm{p}<0.05)$ after germination for 1-4 days.

The effect of germination times on bioactive compounds: Total phenolic compounds: Total phenolic content of GR2, GR3 and GR4 considerably increased from $62.32 \mathrm{mg} 100 \mathrm{~g}^{-1}$ prior to germination to 98.56 , 101.19 and $105.84 \mathrm{mg} 100 \mathrm{~g}^{-1}$, respectively, after germination (Table 3 ).

$\alpha$-Tocophrol, $\gamma$-tocopherol, $\alpha$ - tocotrienol and $\gamma$ oryzanol: The level of $\alpha$-tocopherol, $\gamma$-tocopherol, $\alpha$ tocotrienol and $\gamma$-oryzanol in BR were $0.96,0.38$ and

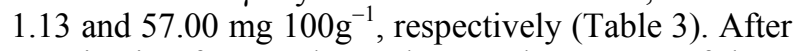
germination for one day or longer, the amount of these compound was improved significantly and reached to the maximum after the second day of germination; i.e. $1.41-1.16,1.27-1.47,2.00-2.46$ and $80.02-84.00 \mathrm{mg}$ $100 \mathrm{~g}^{-1}$, for $\alpha$-tocopherol, $\gamma$-tocopherol, $\alpha$ - tocotrienol and $\gamma$-oryzanol respectively.

Phytic acid: Phytic acid is the primary compound as phosphorus source in most seeds and cereal grains. Phytic acid before germination was $4.32 \%$ and was substantially decreased to $3.92,3.85,2.07$ and $1.46 \%$ after germination for 2, 3 and 4 days, respectively.

The effect of germination times on antioxidant activity: The influence of germinated rice and ungerminated rice samples on DPPH radical quenching, hydroxyl radical inhibition and preventing of lipid peroxidation from peroxyl radical are expressed as inhibition percentage as concentrationdependent manner and $\mathrm{IC}_{50}$ values which were achieved by developing the logarithmic regression curve obtained by fitting the curve plotted sample concentration against percent inhibition. 
Am. J. Applied Sci., 8 (1): 15-25, 2011

Table 1: Effect of germination times on some physical properties of ungerminated brown rice (BR) and germinated rough rice at different

\begin{tabular}{|c|c|c|c|c|c|}
\hline \multirow[b]{2}{*}{$\begin{array}{l}\text { Germination times } \\
\text { (days) }\end{array}$} & \multicolumn{5}{|c|}{ Physical properties } \\
\hline & $\begin{array}{l}\text { Moisture } \\
\text { content (\%) }\end{array}$ & $\begin{array}{l}\text { Germination rate } \\
(\%)\end{array}$ & $\begin{array}{l}\text { Germinated rice } \\
\text { yield }(\%)\end{array}$ & $\begin{array}{l}\text { Shoot } \\
(\mathrm{mm})\end{array}$ & $\begin{array}{l}\text { Root } \\
(\mathrm{mm})\end{array}$ \\
\hline$\overline{\mathrm{BR}}$ & $11.00 \pm 0.14^{\mathrm{c}}$ & $0.00 \pm 0.00$ & ND & ND & ND \\
\hline 0 (S48) & $40.07 \pm 0.06^{\mathrm{b}}$ & $0.00 \pm 0.00^{\mathrm{d}}$ & $89.20 \pm 3.45$ & $0.00 \pm 0.00^{\mathrm{d}}$ & $0.00 \pm 0.00^{\mathrm{d}}$ \\
\hline 1 (GR1) & $44.24 \pm 0.06^{\mathrm{a}}$ & $43.33 \pm 9.29^{c}$ & $87.97 \pm 1.97$ & $1.30 \pm 0.40^{\mathrm{d}}$ & $0.00 \pm 0.00^{\mathrm{d}}$ \\
\hline 2 (GR2) & $44.35 \pm 0.87^{\mathrm{a}}$ & $88.33 \pm 6.80^{\mathrm{b}}$ & $89.20 \pm 3.45$ & $3.48 \pm 1.11^{\mathrm{c}}$ & $8.81 \pm 3.31^{\mathrm{c}}$ \\
\hline 3 (GR3) & $44.40 \pm 0.13^{\mathrm{a}}$ & $94.67 \pm 8.39^{\mathrm{ab}}$ & $85.57 \pm 3.45$ & $11.18 \pm 2.43^{\mathrm{b}}$ & $21.42 \pm 6.55^{\mathrm{b}}$ \\
\hline 4 (GR4) & $43.33 \pm 0.58^{\mathrm{a}}$ & $99.33 \pm 0.58^{\mathrm{a}}$ & $84.33 \pm 0.95$ & $19.68 \pm 5.12^{\mathrm{a}}$ & $25.98 \pm 7.91^{\mathrm{a}}$ \\
\hline
\end{tabular}

a,b,c,d: Means within columns followed by the same letter are not significant different at $\mathrm{p}<0.05$ ND stands for not detected

Table 2: Effect of germination times (days) on $\alpha$-amylase activity (U $\mathrm{g}^{-1}$ flour$)$, sugars, and protein (\% dry matter)

\begin{tabular}{lclr}
\hline $\begin{array}{l}\text { Germination } \\
\text { time }\end{array}$ & $\begin{array}{l}\alpha \text {-amylase } \\
\text { activity }\end{array}$ & $\begin{array}{l}\text { Reducing } \\
\text { sugar }\end{array}$ & \multicolumn{1}{c}{ Protein } \\
\hline BR & ND & $0.19 \pm 0.008^{\mathrm{e}}$ & $8.69 \pm 0.07^{\mathrm{c}}$ \\
0 (S48) & $1.29 \pm 0.02^{\mathrm{e}}$ & $0.54 \pm 0.003^{\mathrm{d}}$ & $8.15 \pm 0.22^{\mathrm{d}}$ \\
1(GR1) & $13.30 \pm 1.14^{\mathrm{d}}$ & $0.98 \pm 0.001^{\mathrm{c}}$ & $10.85 \pm 1.73^{\mathrm{a}}$ \\
2(GR2) & $25.96 \pm 2.18^{\mathrm{c}}$ & $1.81 \pm 0.007^{\mathrm{b}}$ & $11.08 \pm 0.75^{\mathrm{a}}$ \\
3(GR3) & $38.26 \pm 2.03^{\mathrm{a}}$ & $2.41 \pm 0.002^{\mathrm{a}}$ & $10.33 \pm 0.42^{\mathrm{a}}$ \\
4 (GR4) & $31.42 \pm 1.04^{\mathrm{b}}$ & $2.70 \pm 0.001^{\mathrm{a}}$ & $10.44 \pm 0.54^{\mathrm{a}}$ \\
\hline a,b,c,d,e Means within columns followed by the same letter are not \\
\multicolumn{4}{l}{ significant different at $\mathrm{p}<0.05$ ND stands for not detected }
\end{tabular}

The logarithmic regression equations from each rice product (Table 4) were used to calculate $\mathrm{IC}_{50}\left(\mathrm{mg} \mathrm{mL}^{-1}\right.$, of dry matter), the lower, the better antioxidant activity because it requires a lower amount of antioxidant to scavenge $50 \%$ of free radicals. The antioxidant capacities of rice samples were compared to standard antioxidants (BHA and $\alpha$-tocopherol). The coefficient of determination $\left(\mathrm{R}^{2}\right)$ of all samples including standard antioxidants indicated a good fit (data not shown), ranged between 0.975 and $0.993(97.50-99.30 \%$ of the total variation in inhibition percentage can be explained by the relationship between concentration and inhibition).

The correlation between bioactive compounds determined and antioxidant activity of germinated rice, as expressed by the correlation coefficient (r) values, is indicated in Table 4. The negative linear correlations were found between all bioactive compounds and antioxidant activity. Total phenolic compounds, $\alpha$ tocotrienol and $\gamma$-oryzanol showed good correlations to all antioxidant activity assays. The correlation coefficient values were ranged from -0.9022 to -0.9167 for total phenolic compounds, from -0.9641 to -0.9723 and from -0.9573-9853 for $\alpha$-tocotrienol and $\gamma$ oryzanol, respectively, whereas $\alpha$-tocopherol and $\gamma$ tocopherol were fairy correlated to all antioxidant activity assays $(\mathrm{r}=-0.6959$ to -0.8014 and -0.7931 0.9001 , respectively).

DPPH radical scavenging activity: The DPPH radical is commonly used for assessment of antioxidant activity in vitro. In the present study, the results revealed that all samples exhibited substantial scavenging activity against DPPH radical as hydrogen-donating agents.

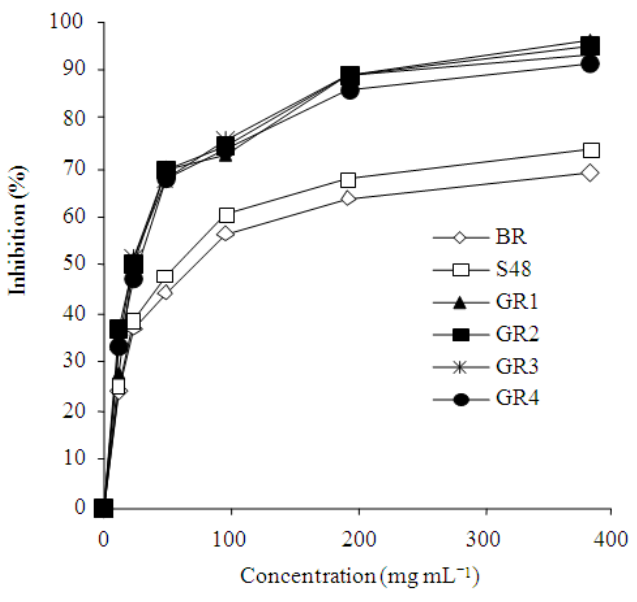

Fig. 1: Dose dependent percent inhibition of DPPH quenching of different germinated rice samples (ungerminated Brown Rice (BR), rough rice soaked in water for 2 days (S48) rough rice soaked in water for 2 days and germinated for 1 day (GR1), rough rice soaked in water for 2 days and germinated for 2 days (GR2), rough rice soaked in water for $48 \mathrm{~h}$ and germinated for 3 days (GR3), rough rice soaked in water for 2 days and germinated for 4 days (GR4))

The dose dependent percent inhibition of DPPH quenching of GR2, GR3 and GR4 were ranged between 33.12 and $94.97 \%$ at the concentrations of 12.00 and $384.00 \mathrm{mg} \mathrm{mL}^{-1}$, respectively, as shown in Fig. 1. The scavenging activity of germinated rice and antioxidant standards as expressed by $\mathrm{IC}_{50}$ values and changes of $\mathrm{IC}_{50}$ related to that of ungerminated brown rice is shown in Table 5. The antioxidant standards revealed the highest activity on DPPH radical scavenging with the $\mathrm{IC}_{50}$ of 23 and $56 \mu \mathrm{g} \mathrm{mL} \mathrm{m}^{-1}$ for BHA and VE, respectively whilst maximum scavenging activity was observed in GR1, GR2, GR3 and GR4 with the $\mathrm{IC}_{50}$ of 17.82, 17.94, 19.68, 21.06 $\mathrm{mg} \mathrm{mL} \mathrm{L}^{-1}$, respectively and the changes of $\mathrm{IC}_{50}$ were between $70.82-75.31 \%$ when related to that of BR. 
Am. J. Applied Sci., 8 (1): 15-25, 2011

Table 3: Comparison of bioactive compounds ( $\mathrm{mg} 100 \mathrm{~g}^{-1}$ dry matter) of ungerminated brown rice (BR) and germinated rough rice at different germination times (days)

\begin{tabular}{lllllll}
\hline Germination time & Total phenolic $^{1}$ & $\alpha$-tocopherol & $\gamma$-tocopherol & $\alpha$-tocotrienol & $\gamma$-oryzanol & Phytic acid (\%) \\
\hline BR & $62.32 \pm 6.41^{\mathrm{c}}$ & $0.96 \pm 0.08^{\mathrm{b}}$ & $0.38 \pm 0.04^{\mathrm{b}}$ & $1.13 \pm 0.18^{\mathrm{c}}$ & $57.00 \pm 3.23^{\mathrm{b}}$ & $4.32 \pm 0.07^{\mathrm{a}}$ \\
0 (S48) & $58.66 \pm 23.5^{\mathrm{c}}$ & $0.91 \pm 0.02^{\mathrm{b}}$ & $0.44 \pm 0.01^{\mathrm{b}}$ & $1.08 \pm 0.04^{\mathrm{c}}$ & $58.94 \pm 5.02^{\mathrm{b}}$ & $4.01 \pm 0.32^{\mathrm{ab}}$ \\
1(GR1) & $87.31 \pm 1.77^{\mathrm{b}}$ & $0.03 \pm .17^{\mathrm{b}}$ & $1.29 \pm 0.08^{\mathrm{a}}$ & $1.66 \pm 0.09^{\mathrm{b}}$ & $74.00 \pm 4.28^{\mathrm{a}}$ & $3.72 \pm 0.78^{\mathrm{b}}$ \\
2(GR2) & $98.56 \pm 7.43^{\mathrm{a}}$ & $1.41 \pm 0.15^{\mathrm{a}}$ & $1.27 \pm 0.11^{\mathrm{a}}$ & $2.26 \pm 0.13^{\mathrm{a}}$ & $80.02 \pm 5.61^{\mathrm{a}}$ & $3.15 \pm 0.63^{\mathrm{b}}$ \\
3(GR3) & $101.19 \pm 4.03^{\mathrm{a}}$ & $1.16 \pm 0.08^{\mathrm{ab}}$ & $1.31 \pm 0.07^{\mathrm{a}}$ & $2.06 \pm 0.17^{\mathrm{a}}$ & $83.45 \pm 7.71^{\mathrm{a}}$ & $2.07 \pm 0.41^{\mathrm{c}}$ \\
4 (GR4) & $102.89 \pm 6.74^{\mathrm{a}}$ & $1.36 \pm 0.13^{\mathrm{a}}$ & $1.47 \pm 0.15^{\mathrm{a}}$ & $2.10 \pm 0.12^{\mathrm{a}}$ & $84.00 \pm 8.93^{\mathrm{a}}$ & $1.46 \pm 0.12^{\mathrm{d}}$ \\
\hline
\end{tabular}

${ }_{\mathrm{a}, \mathrm{b}, \mathrm{c}}$ : Means within columns followed by the same letter are not significant different at $\mathrm{p}<0.05^{1}$ : Total phenolic content was expressed as mg gallic acid equivalents (GAE) $\mathrm{g}^{-1}$ (rice flour)

Table 4:Correlation coefficients (r) of linear regression between the bioactive compounds and the antioxidant capacity of rice

\begin{tabular}{llll}
\hline & \multicolumn{2}{l}{ Correlation coefficients } & \\
Bioactive & DPPH & $\begin{array}{l}\text { Hydroxyl } \\
\text { rompounds }\end{array}$ & $\begin{array}{l}\text { Lipsay } \\
\text { assal peroxidation }\end{array}$ \\
\hline $\begin{array}{l}\text { Total phenolic } \\
\text { compounds }\end{array}$ & -0.9167 & -0.8922 & -0.91480 \\
$\alpha$ - Tocopherol & -0.8014 & -0.6959 & -0.71980 \\
$\gamma$-tocopherol & -0.9001 & -0.7931 & -0.84020 \\
$\alpha$-tocotrienol & -0.9723 & -0.9641 & -0.97251 \\
$\gamma$ - Oryzanol & -0.9253 & -0.9573 & -0.96630 \\
\hline
\end{tabular}

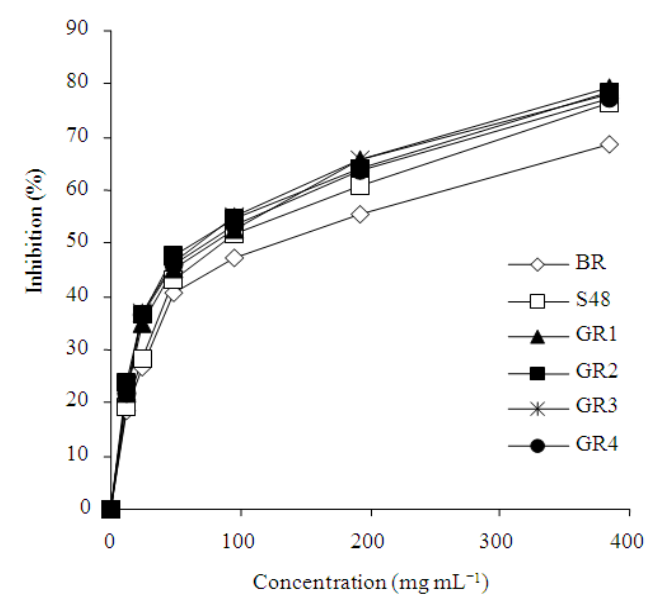

Fig. 2: The dose dependent percent inhibition of hydroxyl radical scavenging of germinated rice (ungerminated brown rice $(\mathrm{BR})$, rough rice soaked in water for 2 days $(\mathrm{S} 48)$ rough rice soaked in water for 2 days and germinated for 1 day (GR1), rough rice soaked in water for 2 days and germinated for 2 days (GR2), rough rice soaked in water for $48 \mathrm{~h}$ and germinated for 3 days (GR3), rough rice soaked in water for 2 days and germinated for 4 days (GR4))

Hydroxyl radical scavenging activity: The dose dependent percent inhibition of hydroxyl radical as an indicator of antioxidant activity and the $\mathrm{IC}_{50}$ of rice samples are indicated in Fig. 2 and Table 5.

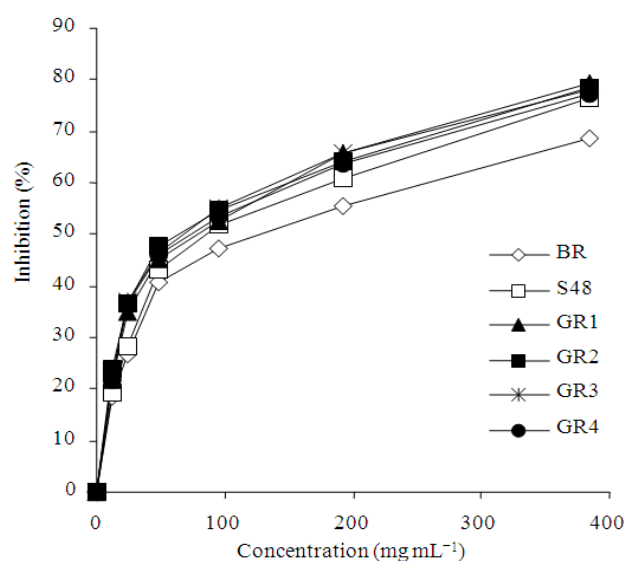

Fig. 3: The dose dependent percent inhibition of peroxyl radical of germinated rice samples (ungerminated brown rice (BR), rough rice soaked in water for 2 days (S48) rough rice soaked in water for 2 days and germinated for 1 day (GR1), rough rice soaked in water for 2 days and germinated for 2 days (GR2), rough rice soaked in water for $48 \mathrm{~h}$ and germinated for 3 days (GR3), rough rice soaked in water for 2 days and germinated for 4 days (GR4))

GR1, GR2, GR3 and GR4 possessed the highest hydroxyl radical scavenging at all concentrations whereas BR showed the lowest scavenging activity. The hydroxyl radical scavenging activities of the germinated rough rice was increased in a dose dependent manner ranged from the $12.00-396.00 \mathrm{mg} \mathrm{mL}^{-1}$ concentration.

Lipid peroxidation assay: The inhibition of lipid peroxidation dose dependence of different rice samples is shown in Fig. 3. It was observed that BR showed smallest effect significantly on lipid peroxidation inhibition compared with that of other rice products. The greatest inhibition was detected in GR1, GR2, GR3 and GR4 (Table 5). The $\mathrm{IC}_{50}$ value of was changed between $72.23-76.40 \%$ compared with that of BR $(0 \%)$. The rough rice germinated for 1-4 days after soaking for 2 days prevent lipid peroxidation more effectively than those of S48 and BR. 
Am. J. Applied Sci., 8 (1): 15-25, 2011

Table 5: The $\mathrm{IC}_{50}$ values, and the changes of $\mathrm{IC}_{50}$ values of ungerminated brown rice (BR) and rough rice germinated with different germination times (days)

\begin{tabular}{|c|c|c|c|c|c|c|}
\hline \multirow[b]{2}{*}{$\begin{array}{l}\text { Germination } \\
\text { time (days) }\end{array}$} & \multicolumn{2}{|l|}{ DPPH } & \multicolumn{2}{|l|}{ Hydroxyl radical } & \multicolumn{2}{|l|}{ Lipid peroxidation } \\
\hline & $\begin{array}{l}\mathrm{IC}_{50} \\
\left(\mathrm{mg} \mathrm{mL}^{-1}\right)\end{array}$ & $\begin{array}{l}\text { Change } \\
(\%)^{1}\end{array}$ & $\begin{array}{l}\mathrm{IC}_{50} \\
\left(\mathrm{mg} \mathrm{mL}^{-1}\right)\end{array}$ & $\begin{array}{l}\text { Change } \\
(\%)\end{array}$ & $\begin{array}{l}\mathrm{IC}_{50} \\
\left(\mathrm{mg} \mathrm{mL}^{-1}\right)\end{array}$ & $\begin{array}{l}\text { Change } \\
(\%)\end{array}$ \\
\hline$\overline{\mathrm{BR}}$ & $72.18 \pm 4.55^{\mathrm{a}}$ & 0.00 & $73.43 \pm 4.55^{\mathrm{a}}$ & 0.00 & $112.10 \pm 9.50^{\mathrm{a}}$ & 0.00 \\
\hline $0(\mathrm{~S} 48)$ & $58.61 \pm 1.39^{b}$ & 19.53 & $48.16 \pm 4.55^{\mathrm{b}}$ & 34.41 & $83.83 \pm 6.44^{\mathrm{b}}$ & 25.22 \\
\hline $1(\mathrm{GR} 1)$ & $17.82 \pm 1.22^{\mathrm{c}}$ & 75.31 & $29.51 \pm 1.55^{\mathrm{c}}$ & 59.81 & $31.13 \pm 2.85^{\mathrm{bc}}$ & 72.23 \\
\hline 2(GR2) & $17.94 \pm 1.35^{\mathrm{c}}$ & 75.15 & $27.84 \pm 1.92^{\mathrm{c}}$ & 62.08 & $28.04 \pm 1.67^{\mathrm{c}}$ & 74.99 \\
\hline 3(GR3) & $19.68 \pm 1.05^{\mathrm{c}}$ & 72.73 & $24.79 \pm 1.05^{\mathrm{c}}$ & 66.23 & $26.45 \pm 1.05^{\mathrm{c}}$ & 76.40 \\
\hline 4 (GR4) & $21.06 \pm 2.19^{\mathrm{c}}$ & 70.82 & $26.11 \pm 1.05^{\mathrm{c}}$ & 64.44 & $29.34 \pm 1.05^{\mathrm{c}}$ & 73.83 \\
\hline $\mathrm{BHA}^{2}$ & $11.44 \pm 1.41\left(\mu \mathrm{g} \mathrm{mL}^{-1}\right)$ & & $14.93 \pm 1.05\left(\mu \mathrm{g} \mathrm{mL}^{-1}\right)$ & & $19.21 \pm 1.05\left(\mu \mathrm{g} \mathrm{mL}^{-1}\right)$ & \\
\hline$\alpha$-tocopherol & $24.08 \pm 1.37\left(\mu \mathrm{g} \mathrm{mL}^{-1}\right)$ & & $19.37 \pm 1.05\left(\mu \mathrm{g} \mathrm{mL}^{-1}\right)$ & & $21.18 \pm 1.05\left(\mu \mathrm{g} \mathrm{mL}^{-1}\right)$ & \\
\hline
\end{tabular}

a,b,c,d: Means within columns followed by the same letter are not significant different at $\mathrm{p}<0.05$; ${ }^{1}$ : Changes of $\mathrm{IC}_{50}$ of rice samples are related to those of BR; ${ }^{2}$ : BHA stands for butylated hydroxyanisole

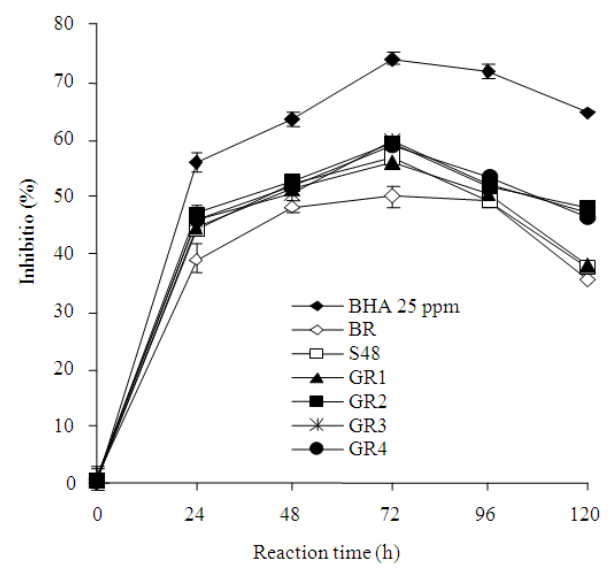

Fig. 4: Inhibition rate (\%) of rice samples and antioxidant standards on peroxyl radical during incubate in thiocyanate system (ungerminated brown rice (BR), rough rice soaked in water for 2 days (S48) rough rice soaked in water for 2 days and germinated for 1 day (GR1), rough rice soaked in water for 2 days and germinated for 2 days (GR2), rough rice soaked in water for $48 \mathrm{~h}$ and germinated for 3 days (GR3), rough rice soaked in water for 2 days and germinated for 4 days (GR4))

Linoleic acid emulsion system-thiocyanate method: The antioxidant activity of the rice products, to prevent peroxidation of linoleic acid, was evaluated by the thiocyanate method in the emulsion system. The results are presented in Fig. 4. The highest percentage of inhibition, of all samples, was indicated at the incubation time of $72 \mathrm{~h}$ and was decreased after $96 \mathrm{~h}$ of reaction time. The greatest inhibition rate $(74.12 \%)$ was found in BHA $25 \mathrm{ppm}$ at the reaction time of $72 \mathrm{~h}$ whereas the inhibition rate (at $72 \mathrm{~h}$ ) of S48, GR1, GR2, GR3 and GR4 was 56.77, 55.89, 59.46, 59.88, $58.86 \%$, respectively, significantly higher than that of BR (50.04\%).

\section{DISCUSSION}

The improvement of reducing sugar in germinated rice was due to the hydrolysis of starch content by $\alpha$ amylase activated during germination process; the reducing sugar content of the endosperm was increased dramatically as $\alpha$ - amylase increased in activity. These results were similar to that reported by Veluppillai et al. (2009). The protein content was slightly increased this can be due to during germination process, several enzymes are activated and some non protein nitrogen substances such as nucleic acids are produced; therefore these can cause protein level to be increased.

The level of total phenolic compounds of the present study was comparable with those reported by De Mira et al. (2009) and Moongngarm and Saetung (2010). The increase of phenolic compounds in the germinated rough rice can be explained by an increase in the amount of free forms from enzyme hydrolysis, due to the breakdown of the cell wall, during germination. Therefore, hydrolysable phenolic compounds obtained from germinated rice can be potentially higher than that of ungerminated rice and more available for human when consumed.

The level of $\alpha$-tocopherol, $\gamma$-tocopherol, $\alpha$ tocotrienols and $\gamma$-oryzanol in BR was slightly differed from those studied by Ha et al. (2006) and Sie-Cheong et al. (2009), in the case of $\gamma$-oryzanol, depending on rice cultivars. The results of the effect of germination on bioactive compounds revealed that the highest level of these compounds was found in the GR2, GR3 and GR4, whilst the lowest was observed in the BR. These results may due to the activity of several enzymes during germination degrade macro molecules and develop new compounds essential for seedling, leading to the liberation, solubilization of bound components and accumulation of some compounds. For the beneficial, tocopherols and $\gamma$-oryzanol are main antioxidants presenting in the bran layer of the rice kernel 
(Iqbal et al., 2005; Lilitchan et al., 2008). These bioactive compounds protect rice oil from oxidation, inhibits peroxidation of lipid mediated by iron or UV irradiation and has been shown to lower blood cholesterol (Rohrer and Siebenmorgen, 2004). Moreover, the potent antioxidants help to prevent cancers and protect biological molecules and tissue from oxidative damage (Yoshida et al., 2003). During the germination of the rough rice, the amount of phytic acid decreased in response to increases in phytase activity. This activity is involved with the conversion of phytic acid to myoinositol and phosphoric acid for seedling. The increasing of phytase activity may account for the reducing of phytic acid, therefore lower phytic acid content was observed in GR1, GR2, GR3 and GR4. These results were similar to the studied documented by Centeno et al. (2001).

Germinated rice products contained high amount of several kinds of antioxidants. According to this study, total phenolic compounds, tocopherols, tocotrienols and $\gamma$-oryzanol were antioxidants investigated. These compounds attribute to the inhibition effect and are capable of stabilizing free radicals. From the study on the correlation between bioactive compounds and antioxidant activity, the negative correlation coefficient values were obtained due to the correlation was performed using the content of each bioactive compound and the $\mathrm{IC}_{50}$ values of each antioxidant activity tested method. The lower $\mathrm{IC}_{50}$ values, the better antioxidant activity because it requires a lower amount of bioactive compound to reduce $50 \%$ of free radicals. These results were similar to the study of Sun et al. (2000) who found that there was a direct relationship between total phenolic content and total antioxidant activity in extracts of fruits. Total phenolic compounds naturally occur in the plant kingdom as secondary metabolic products and contain a phenolic hydroxyl group, which has an antioxidative effect through interactions with its phenol ring and its resonance stabilization effect. According to Iqbal et al. (2005), tocopherols and tocotrienols, which comprise vitamin $\mathrm{E}$ and $\gamma$-oryzanol are the main antioxidants present in the rice especially rice bran layer. Antioxidant activity of $\gamma-$ oryzanols is almost 10 times higher than that of tocopherols, while tocotrienols have 40-60 times greater antioxidant power than those of tocopherols in different biological systems (Iqbal et al., 2005). These antioxidants existing in germinated rice significantly inhibited the peroxidation of linoleic acid and acted as strong hydrogendonating agents in the DPPH radical, peroxyl radical in lipid peroxidation and hydroxyl radical.

For antioxidant activity study, four different methods with diverse mechanisms of action were applied. DPPH radical scavenging method: DPPH is characterized as a stable free radical. Antioxidant in germinated rice sample interacted with DPPH radical by either on giving electron or hydrogen atom to DPPH, thus neutralized its free radical character. The color changes from purple to yellow and its absorbance at wavelength 517 decreased (Dasgupta and De, 2004).

For hydroxyl radical scavenging assay, hydroxyl radical degrades the deoxyribose via Fenton reaction leading to the production of complex products which can be evaluated by a Malonaldehyde (MDA). The present of antiradical prevents MDA production. The determination of the hydroxyl radical scavenging capacity of germinated rice products was evaluated the degree of deoxyribose degradation. Lipid peroxidation assay: This assay was used to measure the lipid peroxide formed in egg yolk homogenate as lipid-rich media (Dasgupta and De, 2004). Egg yolk lipids undergo rapid non-enzymatic peroxidation when incubated in the presence of ferrous sulphate. Antioxidants inhibit the peroxidation of linoleic acid and act as a strong electron-donating agent in the $\mathrm{Fe}^{3+}$ to $\mathrm{Fe}^{2+}$ assay. Lipid peroxides are likely involved in numerous pathological events; including inflammation, metabolic disorders and cellular aging (Wiseman and Halliwell, 1996).

On the investigation of dose dependence, the profile of DPPH radical scavenging, hydroxyl radical scavenging and peroxyl radical scavenging of all samples was similar to each other, linearly increased at low concentrations and then declined at higher concentration. This was due to germination and the treatments, which increased the antioxidant compounds, such as phenolic compounds, $\gamma$-oryzanol and $\alpha$ tocopherol thus improved the antioxidant activity of germinated rice products.

The antioxidant capacity of all germinated and ungerminated rice products of this study was much lower than those of BHA and $\alpha$-tocopherol. This may due to the results reported in this study were expressed as milligram of original weight (dry matter) of germinated rice flour and ungerminated rice flour per milliliter of solvent extracted. The $\mathrm{IC}_{50}$ values of different tested methods were different depending on the mechanism of antioxidants to react with different kinds of free radicals and in diverse tested systems. Therefore, the values of $\mathrm{IC}_{50}$ from different assays should not be compared.

In the linoleic acid emulsion system-thiocyanate method, the antioxidant activity of the rice products, to prevent peroxidation of linoleic acid, was evaluated by the thiocyanate method in the emulsion system. The oxidation of linoleic acid can decompose to several 
secondary oxidation products. These oxidized products reacted with ferrous sulphate to form ferric sulphate, which further reacted with ammonium thiocyanate, to form the ferric thiocyanate and this yielded a red color. The S48, GR1, GR2, GR3 and GR4 expressed more protective effect than that of BR. This may be due to the higher content of bioactive compounds, which corresponded to the greater antioxidant activity. Antioxidant in the rice samples could retard the oxidation of the linoleic acid and therefore, the formation of ferric thiocyanate would be slow (Suja et al., 2005).

Almost all bioactive components determined in this study were slightly declined when germinated for 4 days (GR4) compared with those of GR2 and GR3 and the same trends were also found in its antioxidant activity. These may due to at the 4th day of the germination, the first leaf of germinated seeds broke through the coleoptiles and radicles were much elongated which some of nutrients and bio-molecules are needed for seedling to grow and some are used up. On the other hands, S48 indicated less bioactive compound contents and had weaker antioxidant activity than those of GR1, GR2, GR3 and GR4. These may be due to after the seeds were soaked the biochemical process was just about to begin; therefore, the bioactive compounds and other compounds were not well developed and produced.

\section{CONCLUSION}

The germination time influenced bioactive compounds and antioxidant capacity of rough rice. The ranking of the germinated rough rice obtained from different germination times in terms of the level of bioactive compounds and antioxidant capacity followed the decreasing order: GR2 $>$ GR3 $>$ GR4 $>$ SRR $>$ BR. The higher level of bioactive compounds and stronger antioxidant activity of GR2 and GR3 was useful information for selecting the optimum time to germinate rough rice. Their bioactive compounds and health beneficial properties evaluated through the antioxidant activity could be potentially applied to produce functional foods. However, in the present study, only one cultivar of rice was investigated. In order to apply this information to other rice cultivars or other plant seed species, more specific information, such as germination temperature, may be needed to achieve similar results.

\section{ACKNOWLEDGEMENT}

The researchers gratefully acknowledge Mahasarakham University for providing financial support.

\section{REFERENCES}

Aguilar-Garcia, C., G. Gavino, M. BaraganoMosqueda, P. Hevia and V.C. Gavino, 2007. Correlation of tocopherol, tocotrienol, $\gamma$-oryzanol and total polyphenol content in rice bran with different antioxidant capacity assays. Food Chem., 102: 1228-1232. DOI: 10.1016/j.foodchem.2006.07.012

Akihisa, T., K. Yasukawa, M. Yamaura, M. Ukiya and Y. Kimura et al., 2000. Triterpene alcohol and sterol ferulates from rice bran and their antiinflammatory effects. J. Agricul. Food Chem., 48: 2313-2319. DOI: $10.1021 / \mathrm{jf} 0001350$

AOAC, 1990. Official Methods of Analysis of AOAC International. Iowa State University. http://www.lib.iastate.edu/collections/db/aoacin.ht $\mathrm{ml}$

Banchuen, J., P. Thammarutwasik, B. Ooraikul, P. Wuttijumnong and P. Sirivongpaisal, 2009. Effect of germinating processes on bioactive component of sangyod muang phatthalung rice. Thai J. Agricul. Sci., 42: 191-199.

Centeno, C., A. Viveros, A. Brenes, R. Canales and A. Lozano et al., 2001. Effect of several germination conditions on total $\mathrm{P}$, phytate $\mathrm{P}$, phytase and acid phosphatase activities and inositol phosphate esters in rye and barley. J. Agricul. Food Chem., 49: 3208-3215. DOI: 10.1021/jf010023c

Dasgupta, N. and B. De, 2004. Antioxidant activity of Piper betle L. leaf extract in vitro. Food Chem., 88: 219-224. DOI: 10.1016/j.foodchem.2004.01.036

De Mira, N.V.M., I.L. Massaretto, C. Pascual and U.M.L. Marquez, 2009. Comparative study of phenolic compounds in different Brazilian rice (Oryza sativa L.) genotypes. J. Food Composition Analysis, 22: 405-409. DOI: 10.1016/j.jfca.2008.06.012

Febles, C.I., A. Arias, A. Hardisson, C. RodriquezAlvarez and A. Sierra, 2002. Phytic acid level in wheat flours. J. Cereal Sci., 36: 19-23. DOI: 10.1006/jcrs.2001.0441

Fernandez-Orozco, R., J. Frias, H. Zielinski, M.K. Piskula and H. Kozlowska et al., 2008. Kinetic study of the antioxidant compounds and antioxidant capacity during germination of Vigna radiata cv. emmerald, Glycine max cv. jutro and Glycine max cv. merit. Food Chem., 111: 622-630. DOI: 10.1016/j.foodchem.2008.04.028

Garcia-Estepa, R.M., E. Guerra-Hernandez and B. Garcia-Villanova, 1999. Phytic acid content in milled cereal products and breads. Food Res. Int., 32: 217-221. DOI: 10.1016/S0963-9969(99)00092-7 
Ha, T.Y., S.N. Ko, S.M. Lee, H.R. Kim and S.H. Chung et al., 2006. Changes in nutraceutical lipid components of rice at different degrees of milling. Eur. J. Lipid Sci. Technol., 108: 175-181. DOI: 10.1002/ejlt.200500250

Imsanguan, P., A. Roaysubtawee, R. Borirak, S. Pongamphai and S. Douglas et al., 2008. Extraction of $\alpha$ tocopherol and $\gamma$-oryzanol from rice bran. LWTFood Sci. Technol., 41: 1417-1424. DOI: 10.1016/j.lwt.2007.08.028

Iqbal, S., M.I. Bhanger and F. Anwar, 2005. Antioxidant properties and components of some commercially available varieties of rice bran in Pakistan. Food Chem., 93: 265-272. DOI: 10.1016/j.foodchem.2004.09.024

Johanna, L.W., 1999. Health effects of vegetables and fruit: assessing mechanisms of action in human experimental studies. Am. J. Clin. Nutr., 70: 475-490.

Lilitchan, S., C. Tangprawat, K. Aryusuk, S. Krisnangkura and S. Chokmoh et al., 2008. Partial extraction method for the rapid analysis of total lipids and $\gamma$ oryzanol contents in rice bran. Food Chem., 106: 752-759. DOI: 10.1016/j.foodchem.2007.06.052

Martinez-Villaluenga, C., E. Penas, E. Ciska, M.K. Piskula and H. Kozlowska et al., 2010. Time dependence of bioactive compounds and antioxidant capacity during germination of different cultivars of broccoli and radish seeds. Food Chem., 120: 710716. DOI: $10.1016 /$ j.foodchem.2009.10.067

Moongngarm, A. and N. Saetung, 2010. Comparison of chemical compositions and bioactive compounds of germinated rough rice and brown rice. Food Chem., 122 : $\quad 782-788 . \quad$ DOI: 10.1016/j.foodchem.2010.03.053

Nanua, J.N., J.U. McGregor and J.S. Godber, 2000. Influence of high-oryzanol rice bran oil on the oxidative stability of whole milk powder. J. Dairy Sci., 83: 2426-2431. DOI: 10.3168/jds.S00220302(00)75132-0

Ohtsubo, K., K. Suzuki, Y. Yasui and T. Kasumi, 2005. Bio-functional components in the processed pregerminated brown rice by a twin-screw extruder. J. Food Composition Analysis, 18: 303-316. DOI: 10.1016/j.jfca.2004.10.003

Rohrer, C.A. and T.J. Siebenmorgen, 2004. Nutraceutical concentrations within the bran of various rice kernel thickness fractions. Biosystems Eng., $\quad 88: \quad 453-460 . \quad$ DOI: 10.1016/j.biosystemseng.2004.04.009
Rong, N., L.M. Ausman and R.J. Nicolosi, 1997. Oryzanol decreases cholesterol absorption and aortic fatty streaks in hamsters. Lipids, 32: 303-309. DOI: $10.1007 / \mathrm{s} 11745-997-0037-9$

Ryynanen, M., A.M. Lampi, P. Salo-Vaananen, V. Ollilainen and V. Piironen, 2004. A small-scale sample preparation method with HPLC analysis for determination of tocopherols and tocotrienols in cereals. J. Food Composition Anal., 17: 749-765. DOI: $10.1016 /$ j.jfca.2003.09.014

Sakanaka, S., Y. Tachibana, N. Ishihara and L.R. Juneja, 2005. Antioxidant properties of casein calcium peptides and their effects on lipid oxidation in beef homogenates. J. Agricul. Food Chem., 53: 464-468. DOI: $10.1021 /$ jf0487699

Sereewatthanawut, I., S. Prapintip, K. Watchiraruji, M. Goto and M. Sasaki et al., 2008. Extraction of protein and amino acids from deoiled rice bran by subcritical water hydrolysis. Bioresource Technol., 99: 555-561. DOI: 10.1016/j.biortech.2006.12.030

Sie-Cheong, K., P.H. Yiu, A. Rajan and S.C. Wong, 2009. Effect of Germination on $\gamma$-oryzanol content of selected sarawak rice cultivars. Am. J. Applied Sci., 6: $1658-1661 . \quad$ DOI: 10.3844/ajassp.2009.1658.1661

Somogyi, M., 1952. Notes on sugar determination. J. Biological Chem., 195: 19-23. PMID: 14938350

Suja, K.P., A. Jayalekshmy and C. Arumughan, 2005. Antioxidant activity of sesame cake extract. Food Chem., 213-219. 91: DOI: 10.1016/j.foodchem.2003.09.001

Sun, J., Y.F. Chu, X. Wu and R.H. Liu, 2000. Antioxidant and antiproliferative activities of common fruits. J. Agricul. Food Chem., 50: 7449-7454. DOI: $10.1021 / \mathrm{jf0207530}$

Veluppillai, S., K. Nithyanantharajah, S. Vasantharuba and S. Balakumar et al., 2009. Biochemical changes associated with germinating rice grains and germination improvement. Rice Sci., 16: 240242. DOI: $10.1016 / \mathrm{s} 1672-6308(08) 60085-2$

Watchararuji, K., M. Goto, M. Sasaki and A. Shotipruk, 2008. Value-added subcritical water hydrolysate from rice bran and soybean meal. Bioresource Technol., 99: 6207-6213. DOI: 10.1016/j.biortech.2007.12.021

Wiseman, H. and B. Halliwell, 1996. Damage to DNA by reactive oxygen and nitrogen species: Role in inflammatory disease and progression to cancer. Biochemical J., 313: 17-29. PMID: 8546679 
Xu, Z.M., N. Hua and J.S. Godber, 2001. Antioxidant activity of tocopherols, tocotrienols and $\gamma$-oryzanol components from rice bran against cholesterol oxidation accelerated by 2, 2 '-azobis (2methylpropionamidine) dihydrochloride. J. Agricul. Food Chem., 49: 2077-2081. DOI: $10.1021 / \mathrm{jf} 0012852$
Yoshida, Y., E. Niki and N. Noguchi, 2003. Comparative study on the action of tocopherols and tocotrienols as antioxidant: chemical and physical effects. Chem. Physics Lipids, 123: 63-75. DOI: 10.1016/S0009-3084(02)00164-0 